\title{
Research on the Application of Intelligent Education Based on New Media Environment in the Comprehensive Ability Training of Mechanical Students
}

\author{
Changjun $\mathrm{Wu}^{1, \mathrm{a}}$, Qiaohua Wang ${ }^{1, \mathrm{~b}}$, Ansheng $\mathrm{Li}^{1, \mathrm{c}}$, Xiaoyun Gong ${ }^{1, \mathrm{~d}}$ \\ ${ }^{1}$ School of Mechanical and Electrical Engineering \\ Zhengzhou University of Light Industry \\ Zhengzhou 450002, China \\ a piaoyanggh2003@163.com, ${ }^{\mathrm{b}} 254754449 @$ qq.com, ${ }^{\mathrm{c}} 365145953 @ \mathrm{qq} . c o m,{ }^{\mathrm{d}}$ gxyun2008@ sohu.com.
}

\begin{abstract}
With the development of new media technology, network media has gradually changed the work and learning methods of teachers and students in colleges and universities. The digital transformation of education, such as mobile learning, online learning and new teaching evaluation methods, brings new challenges to the classroom teaching with teachers as the main body. In order to cultivate students' ability of comprehensive application of knowledge and hands-on problem-solving, this paper puts forward a kind of intelligent education mode, which uses the most popular mobile Internet development technology in the new media environment to upload the micro class video combined with the actual production and life to the network, so as to realize students' independent learning without time and place restrictions, and provides a new channel of interaction between teachers and learners anytime and anywhere. Thus, the study of this paper will greatly accelerate the speed of curriculum learning, promote the process of teaching reform in colleges and universities, and bring new help to the improvement of teaching quality and the cultivation of students' comprehensive ability.
\end{abstract}

Keywords-New media; Mechanical student; Comprehensive ability; Intelligent education

\section{INTRODUCTION}

With the development of new media technology, network media has gradually changed the work and learning methods of teachers and students in colleges and universities. The digital transformation of education, such as mobile learning, online learning and new teaching evaluation methods, brings new challenges to the classroom teaching with teachers as the main body.

Since mechanical courses are complex in content, poor in coherence, rich in basic concepts and descriptive knowledge, and lack of strict logic, teachers only teach, and most students just learn mechanically according to the order. Thus, it brings certain difficulties to both teaching and learning; leads to students' lack of enthusiasm for learning, fails to achieve the purpose of talent cultivation in the new form, and brings great trouble to the improvement of students' comprehensive ability. The traditional teaching mode is difficult to meet the needs of the current mechanical engineering personnel training in the course system, teaching content, experimental equipment and experimental means. Although the country has made great reforms in the education system, and incorporated technologies based on new modern methods, such as CAD, CAM, etc., into the professional fields[1], due to the limitation of teaching funds, it is unrealistic to pursue new things blindly. In this case, it is imperative to reform the teaching methods of traditional mechanical courses.

In order to cultivate the students' ability of comprehensive application of knowledge and hands-on problem-solving, the university has set up relevant experiments and practical training in the major construction and various courses in order to cultivate the students' comprehensive ability. However, it is a fact that there is a lack of necessary connection between the courses, the ability training is mainly based on individual and local training, the quality elements of scientific and technological innovation are lack of coherence, and there is no teaching plan that integrates special technologies such as machinery, electrical engineering, electronics and control technology together for comprehensive training. It is very obvious that it is an indisputable fact that China's engineering education tends to be too theoretical and neglects the engineering design and production practice, which is particularly prominent in the machinery industry and causes serious harm[2-5].

Therefore, it is imperative to put forward a kind of intelligent education mode, which can upload the micro class video combined with the actual production and life through the new media environment, realize students' independent learning without time and place restrictions, and stimulate students' enthusiasm for learning and innovative thinking. 


\section{APPLICATION BACKGROUND OF INTELLIGENT EDUCATION MODE IN THE CULTIVATION OF STUDENTS' COMPREHENSIVE ABILITY}

Intelligent education is educational informatization and refers to the process of comprehensively and deeply using modern information technology to promote the reform and development of education in the field of education (education management, education teaching and education research)[6]. Its technical features are digitalization, networking, intelligence and multimedia, and its basic features are openness, sharing, interaction and cooperation. It promotes the modernization of education with educational informationization and changes the traditional mode with information technology.

The advantages of implementing the research on intelligent education mode are as follows:

First, the research of micro curriculum teaching mode is extensive. With the rise of micro curriculum, micro curriculum production and teaching will become the necessary modern educational technology skills for teachers to engage in teaching. "Micro course" refers to the whole process of wonderful teaching and learning activities carried out by teachers around a certain knowledge point (key and difficult points) or teaching links in the process of classroom and external education and teaching based on the video as the main carrier according to the new curriculum standards and teaching practice requirements. The research of micro-course teaching mode can innovate the education concept, teaching mode and teaching strategy, promote the deep integration of information technology and teaching, create an open, active and innovative learning environment for students, use modern education technology, use reasonable pictures, video demonstrations and voice explanations, stimulate students' interest in learning to the greatest extent, and make students easy to accept. In general traditional teaching, the most important thing to pay attention to is to make students accept and learn knowledge. If students are in the position of passive acceptance and do not pay attention to the cultivation of students' active learning ability, the classroom teaching effect will be dull and poor, and students' learning of knowledge will not achieve the expected effect. Moreover, if a certain knowledge point is taught, let students pass the form of pictures and videos first To understand its situation in real life and explain it in class can not only stimulate students' interest in learning, increase their understanding of the knowledge, but also improve the teaching effect and achieve the purpose of teaching.

Second, the application of hardware equipment is very convenient. With mobile communication entering the $4 \mathrm{G}$ era, smart phones with computer functions have become the standard for students. In order to facilitate students to use smart phones to watch micro class resources online, consult learning courseware, complete related interactive homework and report assessment, real-time application software is born. Based on this new media environment, students can use the fragmented time for mobile learning without the constraints of time and place, which caters to the digital era of knowledge explosion and the era of high-speed and fast-paced.
Third, teachers and students in colleges and universities generally have better learning and acceptance ability for new things. The core of applying intelligent education mode to the mechanical professional classroom is not technology, but the transformation of education concept. That is to say, from teachers as the main body in the past to students as the center today. Some ideas, such as choosing the network communication channels that college students like, communicating and talking with students in relevant platforms, and building "micro classroom" with students on the intelligent platform by breaking up the classroom teaching for a long time in the past, can set up a good mentality for college teachers and take positive actions to promote the teaching reform of mechanical specialized courses and even personnel training, At the same time, it helps to improve the teaching quality of colleges and universities.

\section{THE IMPLEMENTATION OF INTELLIGENT EDUCATION IN THE COMPREHENSIVE ABILITY OF MECHANICAL STUDENTS}

The purpose of mechanical course teaching is to cultivate students' ability to solve practical problems. For example, when teaching "how to establish the differential equation of automobile suspension system" in the mechanical specialty course "Fundamentals of control engineering", if the system diagram and the simplified diagram can run synchronously through the form of animation, the students will have an intuitive understanding, so that when teaching "how to establish the differential equation of the system" in the classroom, it will be much simpler, and complex problems can also be simplified through this way. In view of the above similar problems, this study will carry out work from the following three aspects:

\section{A. Research on the creation of micro-course resources}

According to the specific content of the course, the teaching design is carried out, including the design of teaching scheme, teaching video clip and teaching auxiliary courseware, etc. the resource unit of micro-course is constructed by using the existing teaching technology. Through the combination of micro-course construction and information level, it can stimulate students' interest in learning, cultivate students' awareness of obtaining information by means of information, promote students' independent learning, and achieve the goal of serving teaching.

\section{B. Research on the construction of intelligent education platform}

The construction of intelligent education platform can send text, picture, voice, video, image and text messages to specific groups, and also realize all-round communication and interaction with the platform. The sending and online communication of micro course resources promote the students' independent learning, thus providing a new channel for the teaching and learning of mechanical courses.

\section{Research on the implementation of blended Learning}

Based on the intelligent education platform, the teaching mode of mechanical courses has been transformed into a hybrid 
teaching mode of "teacher led, student-centered" classroom teaching and "student active, teacher guided" off-class autonomous learning, which truly realizes the interaction between teachers and learners at any time and anywhere, and learning is possible everywhere; the interaction content between teachers and learners has changed from single to rich, with multiple ways; The benefits of interaction between teachers and learners have become wider, but the intensity of interaction between teachers and learners has weakened

\section{Trial Implementation of teaching mode}

In the cultivation of students' comprehensive ability, students' learning habits should be corrected first. Because good habits will form a good character and affect students' ability of research and exploration. However, influenced by traditional behavior, students have been used to passively accept the existing knowledge instilled by teachers. In order to completely change the learning state of students, fully mobilize the initiative, enthusiasm and creativity of students in the learning process, teachers must carefully organize, fully cultivate students' habit of self-study, and cultivate their own habit of acquiring knowledge. Otherwise, students' innovation ability cannot be cultivated. Secondly, to cultivate the comprehensive ability of college students, they should be not only let learn scientific theories and knowledge, but also let contact the analysis and management of large-scale complex system. This requires students to exercise their ability in a large number of practices, and the best way to implement these is to let students show a dominant position in the whole process. College Students' scientific and technological activities, college students' innovative experiments, curriculum design, and various scientific and technological competitions are the best ways. These activities are project-driven. They not only examine students' technology, but also their innovative ideas, which are conducive to the creativity and imagination of students and greatly enriches their innovation passion.

\section{CONCLUSION}

In the new media environment, using the most popular mobile Internet development technology, this paper studies the new method of intelligent teaching mode of mechanical professional courses, providing a new channel for teachers and learners to interact anytime and anywhere, which will greatly speeds up the speed of course learning, promote the process of teaching reform in colleges and universities, and help improve the quality of teaching in Colleges and universities.
The intelligent education mode mentioned in this paper makes the interaction between teachers and students from a single content to a rich, diverse ways, and the benefits of the interaction between teachers and students become broad. It highly integrates the teaching concept of "combination of theory and practice", highlights the key and difficult points, realizes the creation of micro class resources, strengthens the cultivation of students' practical ability and comprehensive quality, realizes the organic combination of intelligent education platform and teaching mode of mechanical specialized courses, and truly realizes the interaction between teachers and learners at anytime and anywhere, and makes learning omnipresent possible. Through this kind of education mode, it is helpful for students to form a good habit of independent learning, stimulate their enthusiasm for learning and improve their ability of scientific and technological innovation.

\section{ACKNOWLEDGMENT}

This work was supported by the Teaching reform and research project of Zhengzhou University of Light Industry.

\section{REFERENCES}

[1] Xie, Guizhong, Fannian Meng, Dehai Zhang, et al. "Research of course teaching system reform with the characteristic of light mechanism design." DEStech Transactions on Social Science, Education and Human Science eemt (2017).

[2] Liangwen Wang, Guofu Luo, Wenliao Du, et al. "Study and practice of applicative talents development scheme with features of light industry machinery specialty," 2015 International Conference on Advanced Education and Management (Icaem 2015). Guilin, pp. 259-264, May 2015.

[3] Liangwen Wang, FanNian Meng, Wenliao Du, et al. "Understanding and practice of constructing the school light industry equipment production practice base," 2017 3rd International conference on education and social development (Icesd 2017). Xi' an, pp. 158-160, April 2017.

[4] LiangWen Wang, Feng Zhao, WenLiao Du, et al. "Teaching reform and practice of the curriculum of mechanism design based on innovation ability training," 2016 International Conference on Advanced Education and Management (Icaem 2016). Hangzhou, pp. 259-264, May 2016.

[5] Liangwen Wang, Guofu Luo, and Wenliao Du. "Study and practice of applicative talents development scheme with features of light industry machinery specialty," 2015 International Conference on Advanced Education and Management. Guilin, pp. 1-5, May 2015.

[6] Fannian Meng, Hongwei Li, Zhiling Xiao, et al. "Course Reform and Practice of Interchangeability and Technical Measurement Oriented to Engineering Certification." DEStech Transactions on Social Science, Education and Human Science ESEM (2019). 